\title{
MACC1 is post-transcriptionally regulated by miR-218 in colorectal cancer
}

\author{
Katharina IIm ${ }^{1}$, Steffen Fuchs ${ }^{1}$, Giridhar Mudduluru ${ }^{1,2}$, Ulrike Stein ${ }^{1,2}$ \\ ${ }^{1}$ Experimental and Clinical Research Center, Charité University Medicine Berlin and Max-Delbrück-Center for Molecular \\ Medicine in the Helmholtz Association, Berlin, Germany \\ ${ }^{2}$ German Cancer Consortium (DKTK), Heidelberg, Germany
}

Correspondence to: Ulrike Stein, email: ustein@mdc-berlin.de Giridhar Mudduluru, email: giridhar.mudduluru@mdc-berlin.de

Keywords: colorectal cancer, MACC1, miR-218, epigenetic regulation, alternative polyadenylation

Received: May 20, 2016

Accepted: July 13, 2016

Published: July 23, 2016

\section{ABSTRACT}

Metastasis is a multistep molecular network process, which is lethal for more than $\mathbf{9 0} \%$ of the cancer patients. Understanding the regulatory functions of metastasisinducing molecules is in high demand for improved therapeutic cancer approaches. Thus, we studied the post-transcriptional regulation of the crucial carcinogenic and metastasis-mediating molecule metastasis associated in colon cancer 1 (MACC1). In silico analysis revealed MACC1 as a potential target of miR-218, a tumor suppressor miRNA. Expression of these two molecules inversely correlated in colorectal cancer (CRC) cell lines. In a cohort of CRC patient tissues $(n=59), \operatorname{miR-218}$ is significantly downregulated and MACC1 is upregulated compared with normal mucosa. Luciferase reporter assays with a construct of the MACC1-3'-UTR harboring either the wild type or the mutated miR-218 seed sequence confirmed the specificity of the targeting. miR-218 inhibited significantly MACC1 protein expression, and consistently, MACC1mediated migration, invasion and colony formation in CRC cells. Anti-miR-218 enhanced the MACC1-mediated migration, invasion and colony formation. Similar findings were observed in the gastric cancer cell line MKN-45. Further, we performed methylation-specific PCR of the SLIT2 and SLIT3 promoter, where miR-218 is encoded in intronic regions. The SLIT2 and SLIT3 promoters are hypermethylated in CRC cell lines. miR-218 and SLIT2 expressions correlated positively. Methyltransferase inhibitor 5-Azacytidine induced miR-218 expression and inhibited the expression of its target MACC1. We also determined that MACC1 has alternative polyadenylation (APA) sites, which results in different lengths of $3^{\prime}$-UTR variants in a CRC cell line. Taken together, miR-218 is post-transcriptionally inhibiting the MACC1 expression and its metastasis-inducing abilities.

\section{INTRODUCTION}

Metastasis associated in colon cancer 1 (MACC1) was identified through differential display RT-PCR analysis of normal colon mucosa, colorectal cancer (CRC) and respective metastasis tissue specimens in our group [1]. MACC1 induces the crucial step of carcinogenesis transition from adenoma to carcinoma in mice and human $[2,3]$. In $\mathrm{CRC}$ and its prime metastasized organs liver and lung, MACC1 was found to be significantly upregulated when compared to mucosa and adenoma $[1,4-7]$. The five year metastasis-free survival (MFS) of CRC patients with low
MACC1 expression was $80 \%$, whereas the five year MFS rate dropped down to $15 \%$ for CRC patients with high MACC1 expression. Thus, high expression of MACC1 in tumor specimens served as an independent prognostic marker for MFS $[1,8]$. Since its discovery, numerous studies in a variety of different solid cancer entities such as CRC, gastric and hepatocellular carcinoma, demonstrated that MACC1 serves as a prognostic biomarker for patient tumor progression and metastasis [5, 6, 9-12].

High expression of MACC1 induced proliferation, migration and invasion of cancer cell lines and induced tumor growth and metastasis formation in mice $[1,13]$. 
First, MACC1 was identified as transcriptional regulator of the proto-oncogene c-Met [1]. In the meantime, gain or loss of function experiments revealed additional molecules and signaling axis like Akt, E-Cadherin, c-Myc, GSK3 $\beta$ and caspase 3 to be regulated by MACC 1 [14-18]. Therefore, MACC1 is one of the key regulators of hallmarks of cancer like cell proliferation, apoptosis, metastatic events (migration, invasion, epithelial mesenchymal translation (EMT)) and angiogenesis, as well as its role in cancer cell metabolism [1, 17-21]. microRNAs (miRs) are single-stranded RNAs of 19 to $25 \mathrm{nt}$ length, which mostly bind to the $3^{\prime}$ untranslated regions (UTR) of classical protein coding genes and inhibit the target gene expression either by degrading the respective mRNA or by inhibiting its translation [22]. miRs are also transcriptionally regulated, for example by epigenetic modifications [23, 24]. Loss of regulation control at the transcriptional and post-transcriptional levels of MACC1 lead to its overexpression in numerous cancer entities, which causes cancer progression [11, 25-27].

miR-218 is a tumor suppressor miR, which is downregulated in different cancer entities [28]. The mature miR-218 is encoded in two precursor subtypes miR218_1 and miR-218_2, which both are located in introns of SLIT2 and SLIT3, respectively. The expression status of miR-218 depends on the promoter activity of its host genes [29, 30]. From the literature and gene expression depository databases, like The Cancer Genome Atlas (TCGA) and Gene Expression Omnibus (GEO), we know that miR-218 is downregulated and, simultaneously, MACC1 is upregulated in different cancer entities [11, 28]. In silico predictions revealed that the MACC1-3'UTR contains several predicted binding sites for the miR-218-5p specific target sequence to which it can bind via its specific seed sequence. These findings and the importance of these molecules in cancer disease motivated us to explore the role of miR-218 in the posttranscriptional regulation of MACC1. As a result of our study, we identified that MACC1 and miR-218 expression levels correlated inversely in a panel of CRC cell lines. Further, expression levels of MACC1 and miR-218 were significantly upregulated or downregulated in a cohort of CRC patient specimens, respectively. The miR-218 host genes SLIT2 and SLIT3 are hypermethylated in a panel of CRC cell lines. Overexpression of miR-218 significantly downregulated the MACC1 expression and inhibited the MACC1-induced colony formation, migration and invasion in both $\mathrm{CRC}$ and gastric cancer cell lines. In addition, we revealed that MACC1 possesses alternative polyadenylation (APA) sites. Taken together, these data demonstrate that miR-218 is inhibiting, at least in part, the MACC1-mediated tumor progressive events.

\section{RESULTS}

\section{miR-218 expression correlated inversely with MACC1 expression in CRC cell lines}

To investigate an in vitro relevance of the miR-218and MACC1-expression in CRC cell lines, the expressions of these two molecules were measured at the transcript level. A significant inverse correlation between these two genes $(\rho=-0.818, P=0.002)$ was found in CRC cell lines. MACC1 mRNA and its protein amount, however, were not significantly correlated. For example, among the screened CRC cell lines, SW620 cells had the highest MACC1 protein amount and 31-fold higher mRNA expression compared to SW480 cells. Whereas, Caco-2 and DLD1 cells had moderate endogenous protein amounts when compared with SW620 cells, but the relative MACC1 mRNA expression in Caco-2 and DLD-1 cells was higher than in SW620 cells (Figure 1A). This result shows that MACC1 mRNA expression levels not always correlate with protein expression in the analyzed CRC cell line panel.

To have further insights of the potential inverse miR-218- and MACC1-expression correlation in the clinical situation, we screened a cohort of CRC patient tumor specimens and representative normal mucosa samples. Although no significant inverse correlation was found, miR-218 was significantly downregulated and MACC1 significantly upregulated in tumor tissues compared to the normal mucosa (Figure 1B). Apart from this significant regulation, we did not find any other significant correlation of clinicopathological factors with miR-218 expression. These in vitro and in vivo expression studies of these two genes miR-218 and MACC1 prompted us to investigate the post-transcriptional regulation of MACC1 by miR-218.

\section{The MACC1-3'-UTR is a target for miR-218}

The 6299 nt long 3'-UTR of MACC1 (\#NM_182762) was screened for complementary seed sequences of known miRNAs via in silico prediction tools (TargetScan, RNAHybrid). A high threshold seed sequence for miR-218 at nt 218-224 was found (Figure 2A). Given the results from the expression and in silico analyses, we asked whether the 3'-UTR of MACC1 is a functional target of miR-218. To address this question, we cloned 6016 nt of the $3^{\prime}$-UTR of MACC1, harboring the miR-218 seed sequence, in pmirGLO dual luciferase vector at the $3^{\prime}$-position of a luciferase reporter gene (MACC1-3'-UTR). The MACC1-3'-UTR was co-transfected along with miR-218 into HCT116, SW620 and SW480 cells. The luciferase activity of miR-218-transfected MACC1-3'-UTR was significantly reduced when compared with control-miR (Figure 2B). Similarly, a co-transfection with the mutated miR-218 
seed sequence construct did not show any significant reduction in luciferase activity (in HCT116, SW620) when compared with its control-miR. However, reduced luciferase activity was determined for both wild type and mutated MACC1-3'-UTR co-transfected with miR-218 in SW480, which could be due to additional miR-218 seed sequences within the $6.0 \mathrm{~kb}$ of MACC1-3'-UTR or miR218-mediated secondary effects. Taken together, these data suggest that the $3^{\prime}$-UTR of MACC1 is a functional target for miR-218.
miR-218 regulates the $\mathrm{MACC} 1$ gene expression

In order to corroborate the results of the reporter assay, HCT116, SW620 and SW480 cells were transfected with control-miR, miR-218 or anti-miR-218 (complementary sequence to mature miR-218, which inhibits the function of miR-218 by complementary binding). The transfection efficiency of the miR-218 expression was measured by qRT-PCR (Figure 3A). Expression analyses showed that miR-218 reduced

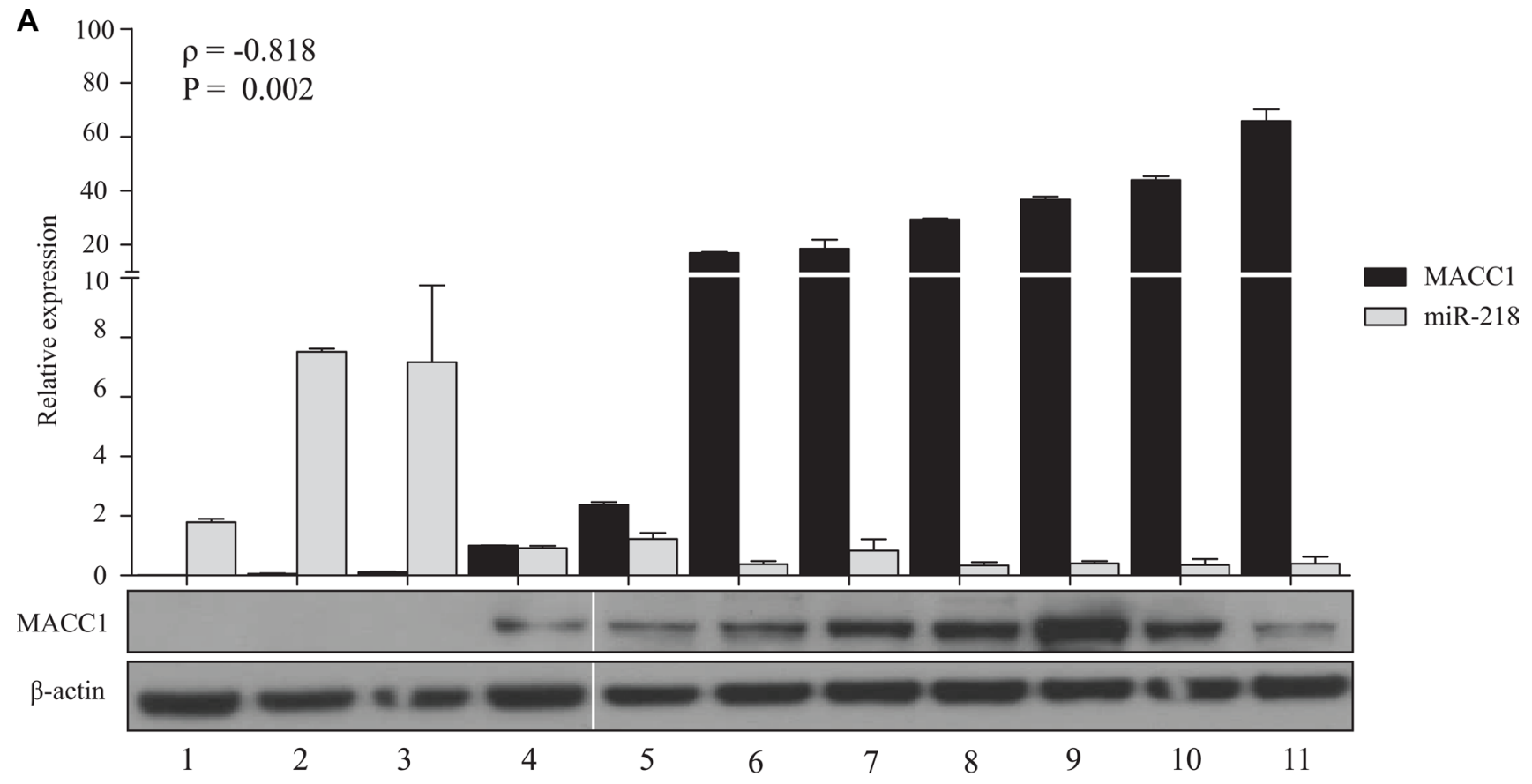

1: Rko; 2: Colo320DM; 3: Colo206f; 4: SW480; 5: HCT116; 6:HCT15; 7: WiDr; 8: HT29; 9: SW620; 10: Caco-2; 11: DLD-1

B



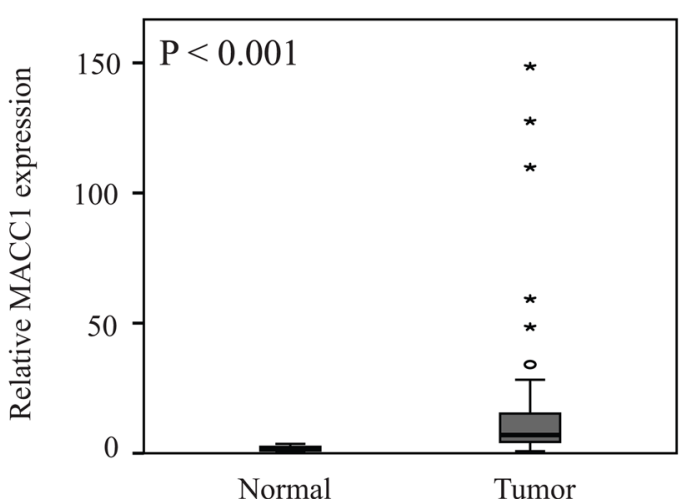

Figure 1: miR-218 and MACC1 expression is inversely correlated in CRC cell lines and are significantly down or upregulated in CRC tumor specimens, respectively. (A) Relative miR-218 and MACC1 expressions in a panel of CRC cell lines were analyzed by qRT-PCR, whereas RNUB6 and RPII served as internal controls. miR-218 and MACC1 expressions are inversely correlated $(\rho=-0.818, P=0.002)$. Protein amounts of MACC1 were screened in the same panel of CRC cell lines. $\beta$-actin served as internal control. (B) miR-218 and MACC1 expression was measured using tumor tissue of 59 CRC patients normalized to representative normal specimens. miR-218 was significantly downregulated $(P=0.016)$ and MACC1 was significantly upregulated $(P<0.001)$ in $\mathrm{CRC}$ tissues. RNUB6 and RPII served as internal controls. 
MACC1-transcript levels, but no changes were observed in anti-miR-218 condition, when compared with the controlmiR. Western blotting confirmed the downregulation of MACC1 protein amounts in cells transfected with miR-218. On the other hand, an upregulation of the MACC1 protein amount was observed in cells transfected with anti-miR-218 in comparison to the control-miR (Figure 3B, 3C). Taken together, these results suggest that miR-218 is regulating MACC1 at the transcript level and most significantly by translation inhibition via binding to its $3^{\prime}$-UTR.

\section{miR-218 inhibits MACC1-induced colony formation, migration and invasion}

To further investigate the functional ability of miR-218 in mediating cancer metastatic events we have performed colony formation, migration and invasion assays by transfecting SW480 cells with either a controlmiR, miR-218 or anti-miR-218 inhibitor. Colony formation assay was performed with soft agar, migration (without matrigel) and invasion (with matrigel) assays were performed with Boyden chamber transwells. Ectopic overexpression of miR-218 significantly reduced the colony formation, migrating and invading capacity of SW480 cells when compared with control-miR expressing cells (Figure 4A-4C). Ectopic overexpression of miR inhibitor anti-miR-218 significantly induced migration (Figure 4A). The cells also showed an induced invasion and colony formation when compared with the controlmiR expressing cells (Figure 4B, 4C). In addition, we also investigated the effect of miR-218 on cell viability, but there was only a minor effect on proliferation detectable in SW480 cells (Supplementary Figure S1A).

Rescue experiments were performed with MACC1 stably expressing SW480 cell line with ectopic overexpression either of $\mathrm{miR}-218$ or the respective control-miR along with the SW480-empty vector (e.v.) control cell line. Transfection efficiency of miR-218 expression and MACC1 expression was measured with qRT-PCR and Western blot analysis, respectively (Figure 4D-4F). In parallel to previous results with SW480 cells, in this setup the SW480-empty vector control cells showed similar results of migration, invasion and colony formation after miR-218 ectopic overexpression. As expected, the SW480-MACC1 cell line induced migration and invasion when compared to SW480-empty vector cell line (Figure 4G, 4H). miR-218 ectopic overexpression resulted in reduced migration and invasion in SW480-empty vector cells, but did not show any significant inhibition of migration and invasion in SW480-MACC1 cells, when compared with its miR-control transfected cells (Figure 4G, 4H). Similar functional effect was observed with colony formation assay (Figure 4I). Additionally, we observed increased ectopic MACC1 expression in miR-218 co-transfected cells comparative to miR-control cells. This could be due to the global effect of miR-218, which might be driving the CMV promoter or stabilizing the mRNA binding proteins. However, other possible molecular mechanisms cannot be ruled out.
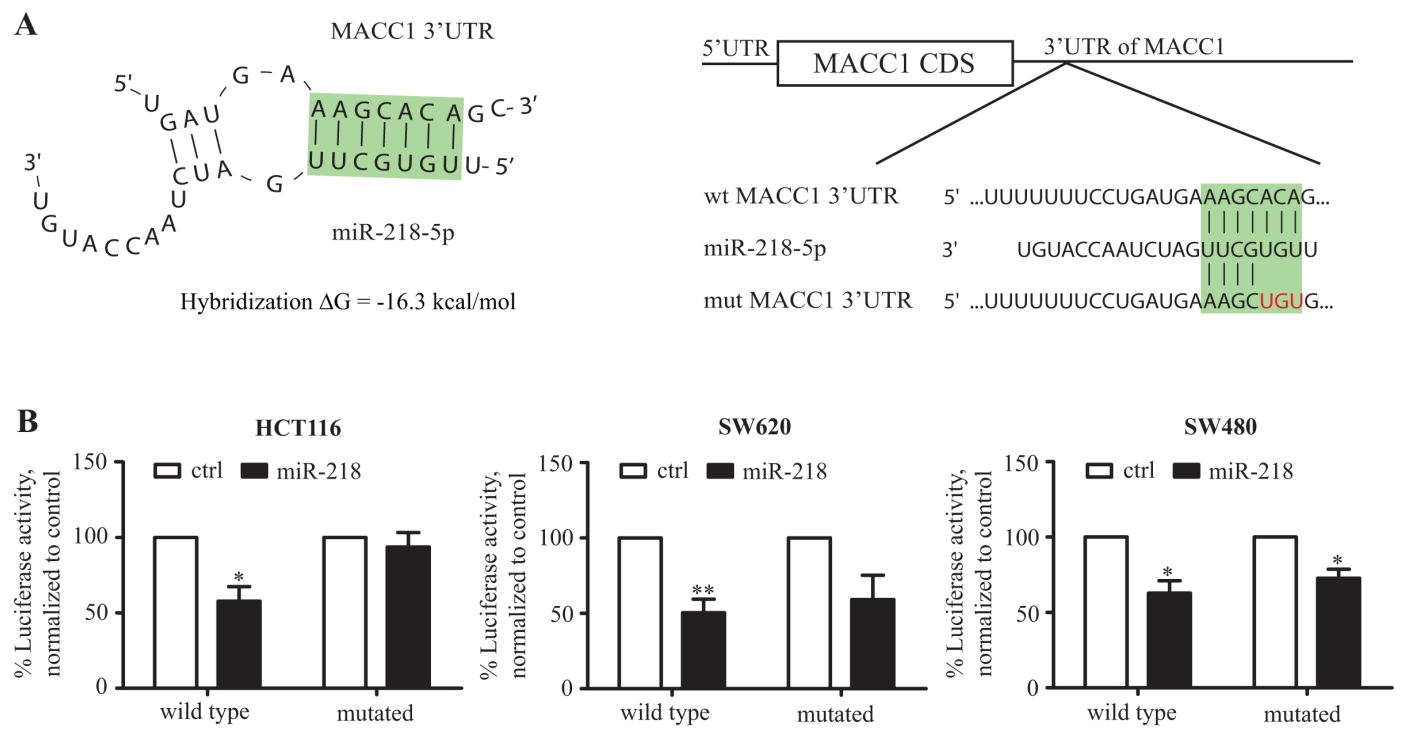

UTR: Untranslated region; CDS: Coding sequence; wt: Wild type; mut: Mutated;

Figure 2: miR-218 targets the MACC1-3'-UTR. (A) Secondary structure prediction (RNAhybrid) of the binding between the seed sequence within the MACC1-3'-UTR (position 218 to $224 \mathrm{nt}$ ) and miR-218 (green-highlighted sequence) revealed a hybridization energy $\Delta \mathrm{G}$ of $-16.3 \mathrm{kcal} / \mathrm{mol}$. Representation of MACC1-3'-UTR with miR-218 binding region and schematic presentation of mutated region of miR-218 seed sequence (red-labled bases were mutated). (B) Luciferase reporter assays of MACC1-3'-UTR wild type and mutated construct in HCT116, SW620 and SW480. Both wild type and mutated MACC1-3'-UTR are co-tranfected either with control-miR (ctrl) or miR-218. Percent luciferase activity was calculated with the respective control $\left({ }^{*} P<0.05 ; * * P<0.01\right)$. 
Taken together, these results indicate that miR218 significantly inhibits different steps of MACC1mediated metastasis including migration, invasion and colony formation. miR-218 induced changes can be in part rescued by MACC1 overexpression which indicates MACC1 as novel target and mediator of the tumor suppressor miR-218 function.

\section{miR-218 inhibited the MACC1 expression and its mediated tumor progressive effects in gastric cancer}

To determine in general the functional role of miR218 for the post-transcriptional regulation of MACC1, we have used an additional cancer entity of the gastrointestinal tract, employing the gastric cancer cell line MKN-45. Consistent with our results performed with CRC cell lines, MACC1 is also a target of miR-218 in gastric cancer cells. Luciferase assay, qRT-PCR and Western blot analyses performed with MKN-45 cells revealed that MACC1 is post-transcriptionally regulated by miR-218 (Figure 5A-5C). In addition, miR-218 reduced the cell viability of MKN-45 cells (Supplementary Figure S1B). We have performed functional experiments with control-miR, miR218, si MACC1 and both miR-218 and si MACC1. Ectopic overexpression of miR-218 or si MACC1 significantly reduced the migration, invasion and colony formation in comparison to the respective experimental controls.
A

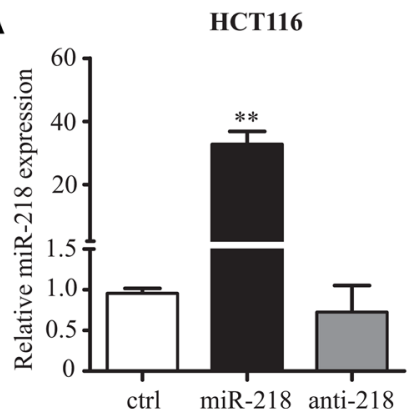

B



C

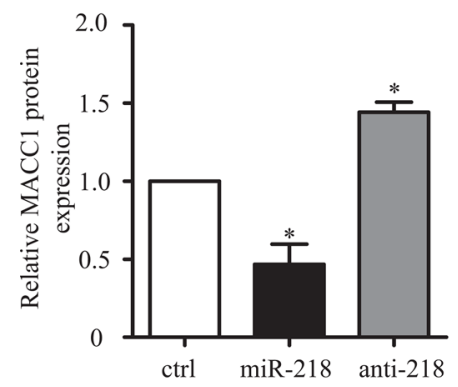

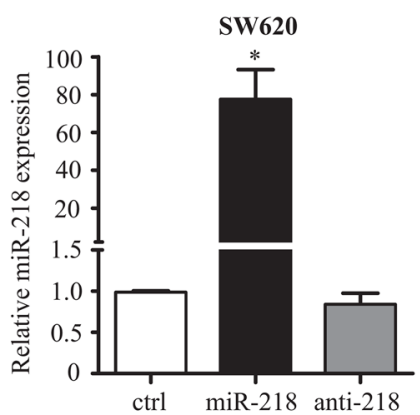
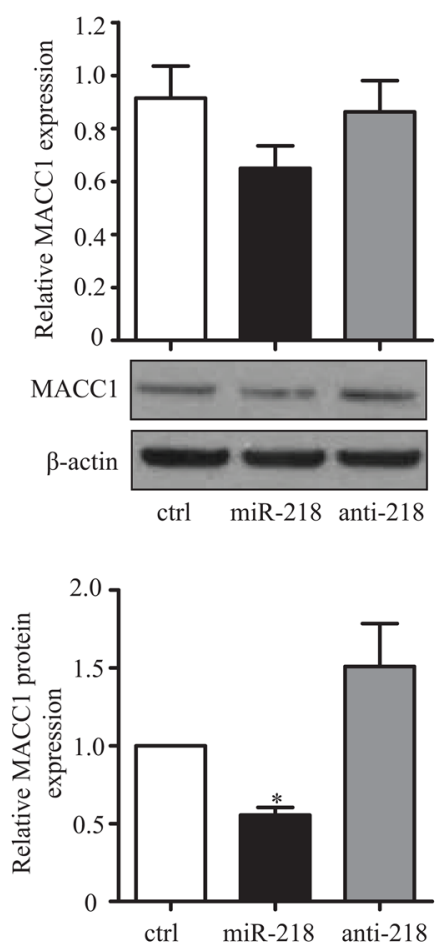
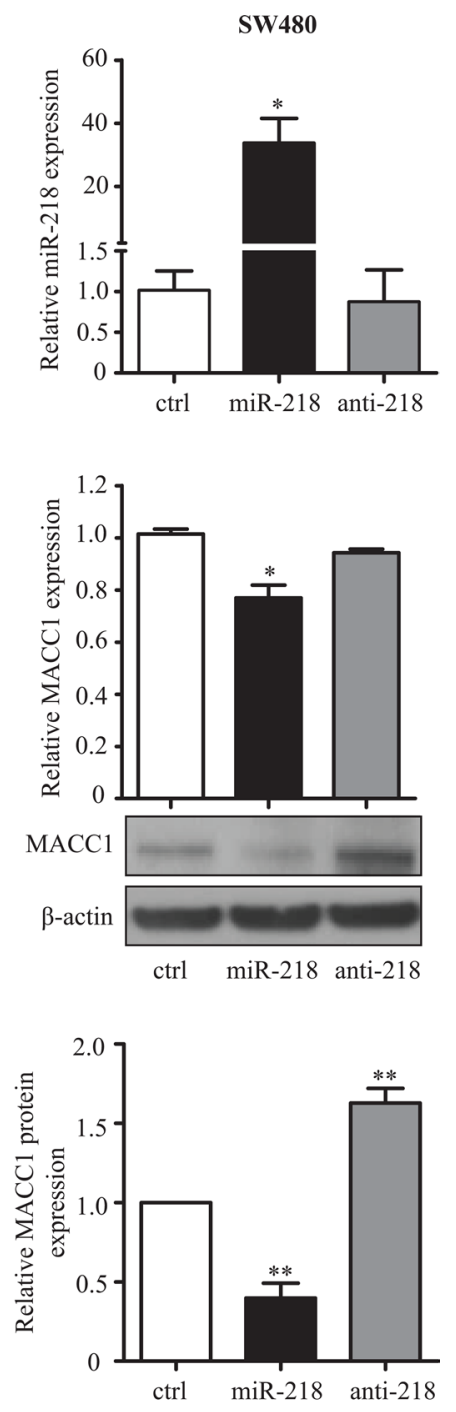

ctrl: Control-miR; anti-218: Anti-miR-218;

Figure 3: miR-218 downregulates MACC1 expression. (A) Expression of miR-218 in the transfected conditions was quantified using qRT-PCR. RNUB6 was used as internal control. (B) MACC1 mRNA and protein expression after transfection of control-miR, miR-218 and anti-miR-218 was determined using qRT-pCR and Western blotting. RPII was used as internal control for MACC1 mRNA expression and $\beta$-actin for Western blotting. Either miR-218 or anti-miR-218 did not regulate the MACC1 mRNA expression significantly, but mainly regulated the MACC1 at protein level, in these three cell lines. $(\mathbf{C})$ Densitometric analysis of MACC1 protein bands normalized to $\beta$-actin represented as a mean value of triplicates, in comparison to the respective control. $(* P<0.05 ; * * P<0.01)$. 
A combination of both miR-218 and si MACC1 further reduced migration, invasion and colony formation when compared with the individual respective control conditions. Ectopic overexpression of miR-218 and knock-down of MACC1 showed the most significant reduction when compared with experimental controls (Figure 5D-5F). This could be due to the lack of MACC1 expression as one of the important post-transcriptional targets of miR-218, indeed miR-218 could actively inhibit other targets. However, one cannot exclude other biological functions mediated due to this condition. These cumulative evidences suggest that miR-218-induced effects on migration, invasion and colony formation in different cancer entities are at least in part a result of the inhibition of the MACC1 expression.
A

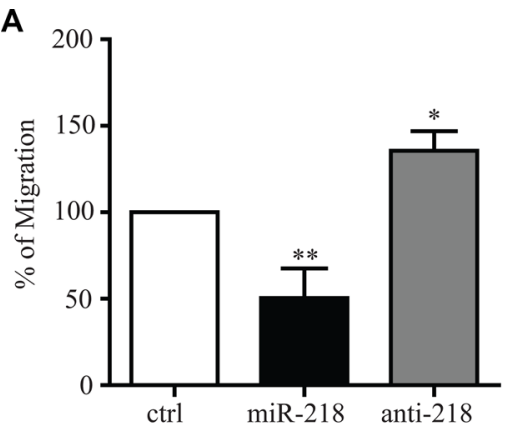

D

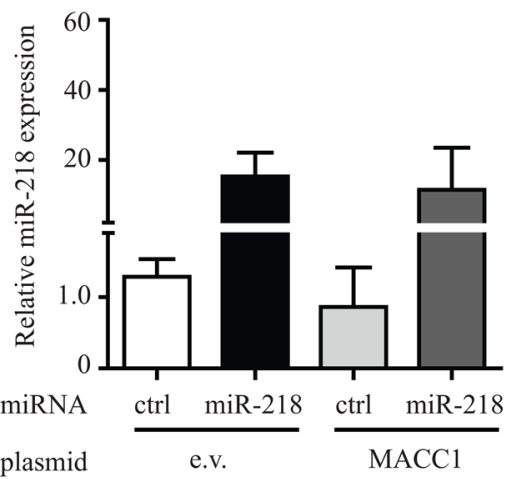

G

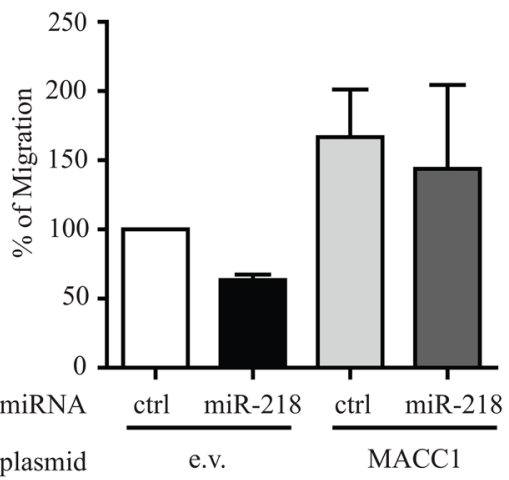

B

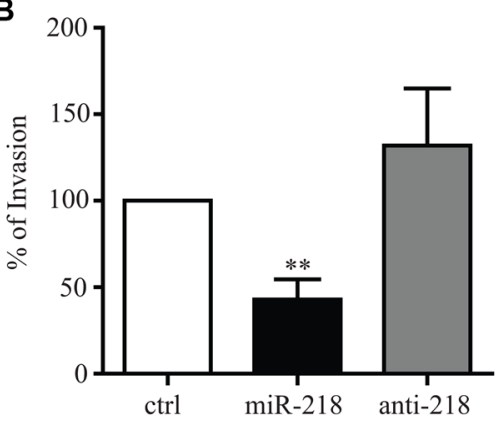

E

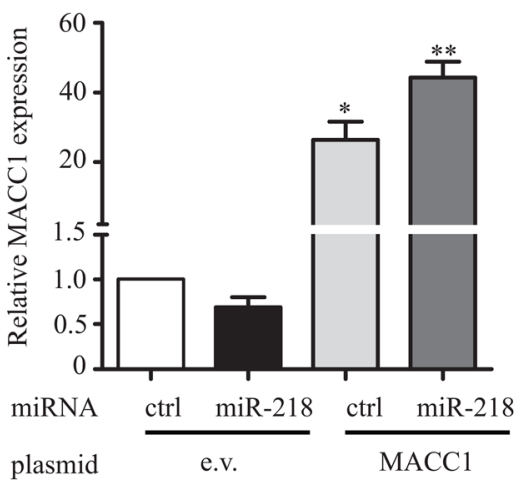

H

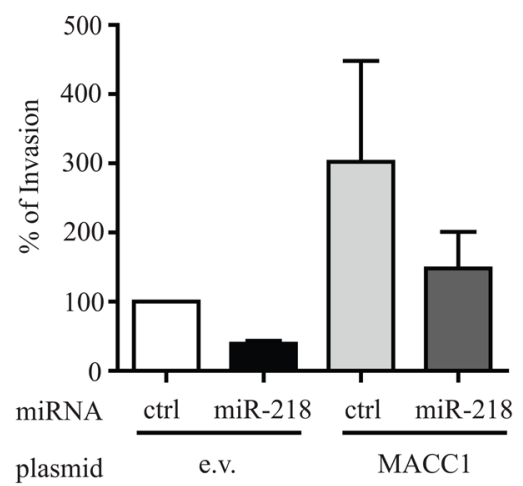



F

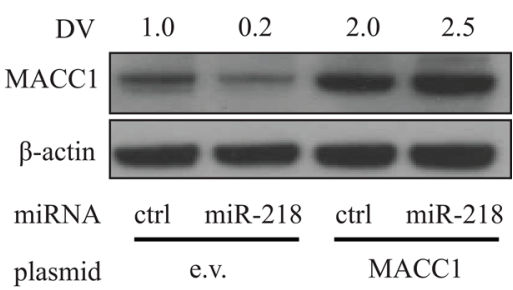

I

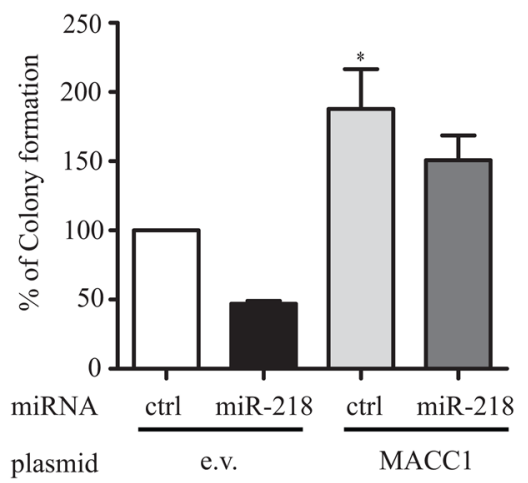

ctrl: Control-miR; anti-218: Anti-miR-218; e.v.: Empty vector; DV: Densitometry values;

Figure 4: miR-218 inhibits the MACC1 mediated tumor metastasis events of CRC. (A, B) SW480 cells were transfected with miR-218 or anti-miR-218. After $48 \mathrm{~h}$ cells were plated on top of the Boyden chambers for migration and matrigel-coated Boyden chambers for invasion. After $15 \mathrm{~h}$ the migrated or invaded cells were measured as described in the materials and methods. (C) After $48 \mathrm{~h}$ of respective control-miR (ctrl), miR-218 and anti-miR-218 (anti-218) transfection, cells were seeded in agar plates and counted as described in material and methods. Numbers of colonies are represented in relation with the control condition as percentage. (D) Relative expression of miR218 after transfection in SW480-empty vector (e.v.) control cells and SW480-MACC1 stably expressing cells. (E, F) MACC1 mRNA and protein expression after miR-218 transfection were quantified using qRT-PCR and Western blotting. (G-I) Migration, invasion and colony formation assays of SW480-e.v and SW480-MACC1 either with control-miR or miR-218. Data are represented as the percentage of migrating or invading cells and colonies as mean \pm SEM of their biological replicates, each experiment performed in three technical replicates. Densitometric analysis of MACC1 protein bands normalized to $\beta$-actin represented as a mean value of triplicates, in comparison to the respective control. ( $\left.* P<0.05,{ }^{*} P<0.01, * * * P<0.001\right)$ 
miR-218 is downregulated in CRC cell lines due to a promoter hypermethylation of its host genes SLIT2 and SLIT3

As determined earlier in this study, miR-218 is downregulated in CRC cell lines and tumor specimens in comparison to normal tissue samples. Moreover, miR-218 is reported to be downregulated across different cancer entities like for example glioblastoma, nasopharyngeal and non-small cell lung cancer [28, 29, 31-33]. It is also known that miR-218 can be epigenetically silenced e.g. by promoter hypermethylation which induces esophageal carcinogenesis [34]. These reports prompted us to study the mechanisms behind the downregulation of miR-218 in CRC. With this regard, we analyzed the expression of the miR-218 and its host gene SLIT2 by qRT-PCR in our panel of CRC cell lines and found that the miR-218 expression correlated positively with the SLIT2 expression (Figure 6A). For better representation of SLIT2 and miR218 expression, $\log _{10}$ transformed expression values were shown as Supplementary Figure S2 $\left(R^{2}=0.95 ; P<0.001\right)$.

This made us to check methylation status of the SLIT2 and SLIT3 promoters with the published primer set by Narayan [30]. For this, DNA was isolated from a panel of CRC cell lines and subjected to bisulfite conversion and to a subsequent methylation-specific PCR. Here, primer pairs specific for the methylated or unmethylated $\mathrm{CpG}$ island promoter region of SLIT2 and SLIT3 were used (Figure 6B). The SLIT3 promoter was hypermethylated in all the eleven screened CRC cell lines. Moreover, the
A

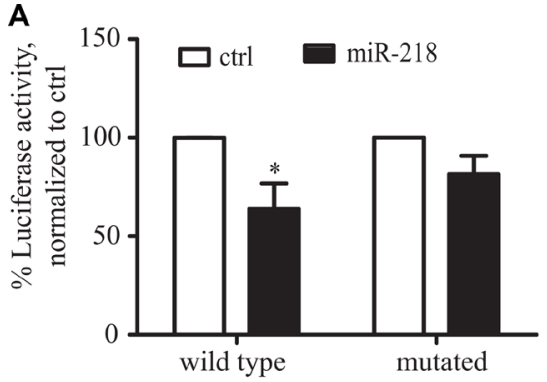

D



B

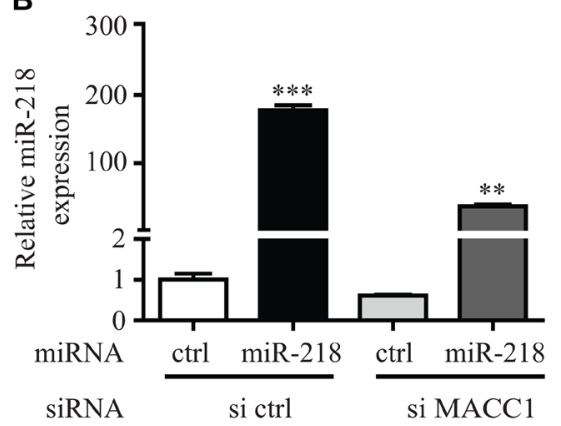

E

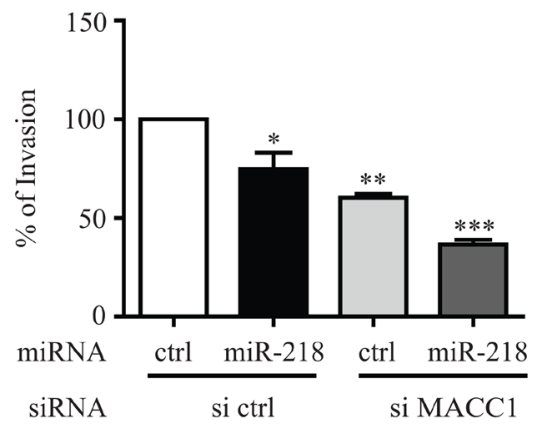

C



$\mathbf{F}$

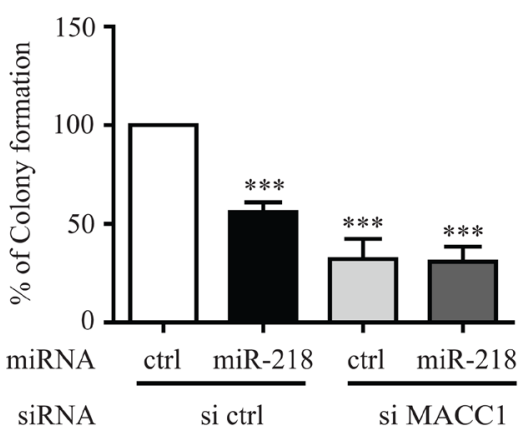

ctrl: Control-miR; si ctrl: Control-siRNA; DV: Densitometry values;

Figure 5: miR-218 inhibits the MACC1 mediated tumor metastasis events of MKN-45, a gastric cancer cell line. (A) Both wild type and mutated MACC1-3'-UTR were co-transfected either with control-miR (ctrl) or miR-218 and luciferase activity were quantified. Percent luciferase activity was calculated with the respective control. (B) Relative expression of miR-218 after transfection in MKN-45 transfected control (ctrl), miR-218, si MACC1 and both miR-218 and si MACC1. (C) MACC1 mRNA and protein amounts after miR-218 and si MACC1 transfection were quantified using qRT-PCR and Western blotting. RPII was used as internal control. $\beta$-actin was used as internal control for Western blotting. (D-F) Migration, invasion and colony formation assays of MKN-45 either with control-miR (ctrl), miR-218, si MACC1 or in combination of miR-218 and si MACC1. Data are represented as the percentage of migrating or invading cells and colonies as mean \pm SEM of their biological replicates, each experiment with three technical replicates. Densitometric analysis of MACC1 protein bands normalized to $\beta$-actin represented as a mean value of triplicates, in comparison to the respective control. $\left({ }^{*} P<0.05\right.$, **P $P<0.01, * * * P<0.001)$ 
SLIT2 promoter was mostly methylated, like for example in CaCo-2 cells, which showed consequently also a relative low miR-218 expression (Figure 6B). However, there were also cell lines with a more unmethylated SLIT2 promoter like Colo206f or Colo320DM, which showed the highest miR-218 expression in the qRT-PCR comparatively (Figure 6B, Figure 1A). To sum up, the hypermethylation of the two host genes SLIT2 and SLIT3 could be the reason for the miR-218 downregulation in most of the screened cell lines.

miR-218, known to inhibit tumor metastasis formation was also significantly downregulated in CRC patient specimens [28, 29]. In this front, we wanted to investigate the clinical relevance of the SLIT2 and SLIT3 promoter methylation in metachronous metastasis positive and negative tumor specimens of CRC patients. Surprisingly, we haven't found any significant change in the methylation pattern of miR-218 host genes or in its expression between these two groups (Figure 6C, 6D). This could mean that a miR-218 downregulation might be an early event in primary tumor progression independent of metastasis formation.

\section{5-Aza treatment reactivates miR-218 expression and inhibits MACC1 expression}

In order to further differentiate the epigenetic regulation mechanism of $\mathrm{miR}-218$ and $\mathrm{MACC} 1$, the two CRC cell lines SW480 and SW620 were treated with a selective inhibitor of DNA methyltransferases 5-aza-2'deoxycytidine (5-Aza). Cells were treated for $72 \mathrm{~h}$ with $2 \mu \mathrm{M} 5$-Aza by changing the medium with the drug or the DMSO control every $24 \mathrm{~h}$, respectively. Interesting results were observed regarding the MACC1-3'-UTR luciferase activity and the MACC1 gene expression after 5-Aza treatment. Both of the cell lines showed an induction of miR-218 and SLIT2 expression (Figure 7A, 7B). Consistently, significantly reduced luciferase activities were observed after 5-Aza treatment (Figure 7C). These observations resulted in significant downregulation of MACC1 in both cell lines at the mRNA and protein level (Figure 7D). This could be due to global effects of 5-Aza on the promoter methylation status of other miRs or transcriptional regulators that might affect the MACC1 expression. These data suggest that the epigenetic downregulation of miR-218 leads to an upregulation of MACC1 at least in part due to the loss of the miR-218 function in CRC cell lines and tumor specimens.

\section{MACC1 possesses alternative polyadenylation (APA) sites}

Recent technical advancement of sequencing methods revealed that protein coding gene transcripts possess alternative polyadenylation (APA), and have shorter 3'-UTR both in cancer cells and in cancer specimens when compared with healthy controls [35-37]. A full length $3^{\prime}$-UTR of a specific gene is unavoidable

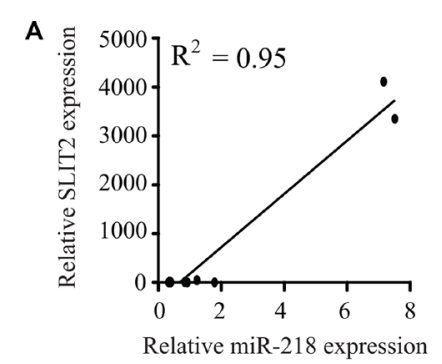

C

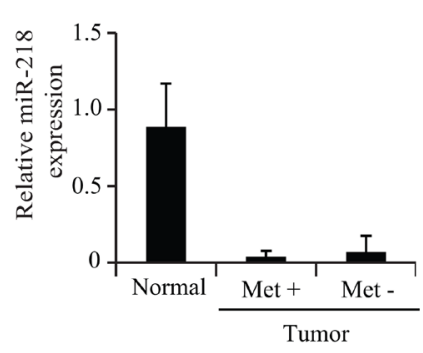



D

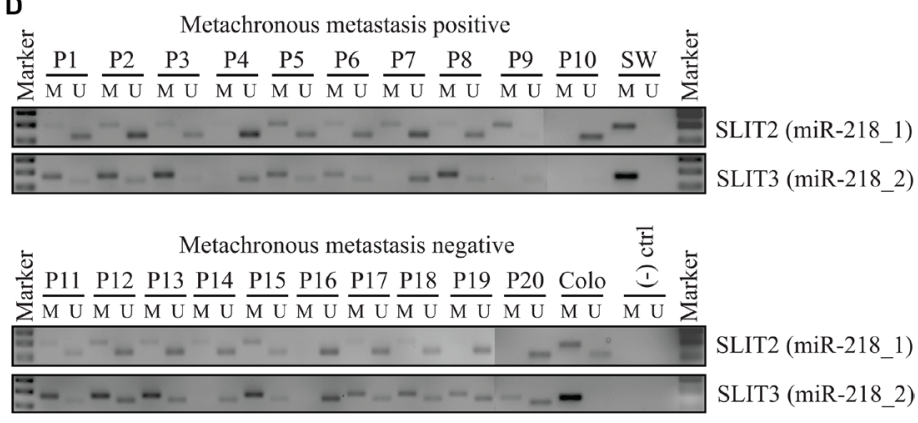

M: Methylated; U: Unmethylated; (-) ctrl: Negative control; P: Patient; SW: SW620, Colo:Colo206f;

Met +: Metachronous metastasis positive; Met -: Metachronous metastasis negative;

Figure 6: Methylation status of miR-218 host genes SLIT2 and SLIT3 promoters in CRC cells and CRC metachronous metastasis positive and negative specimens. (A) miR-218 and SLIT2 expression were measured using qRT-PCR and positively correlated in a panel of CRC cell lines $\left(R^{2}=0.95\right)$. (B) Gel electrophoresis of PCR products of CRC cell lines obtained from methylationspecific PCR for miR-218_1 hosting gene SLIT2 and miR-218_2 hosting gene SLIT3. (C) miR-218 expression in metachronous metastasis positive and negative CRC tumor specimens in comparison to representative normal mucosa. RPII and RNUB6 served as internal controls. (D) Gel electrophoresis of PCR products of CRC tumor specimens obtained from methylation-specific PCR for miR-218_1 hosting gene SLIT2 and miR-218_2 hosting gene SLIT3. 
for a comprehensive post-transcriptional regulation by miRNAs. Further, it is also known that some of the important cancer-related genes have shorter 3'-UTRs in cancer tissue than in normal tissues due to APA sites $[35,38]$. Due to this reason and the important role of MACC1 upregulation in different cancer entities, we have investigated whether MACC1-3'-UTR contains any APA sites (Figure 8A).

We performed 3'-RACE experiment using the CRC tumor cell line SW620 and found that
MACC1 possesses several APA sites in these cells (Figure 8B). SW620 cells have the highest MACC1 protein expression and transcribe the longest 3'-UTR which harbors miR-218 seed sequences. Therefore, this regulatory mechanism does not affect the posttranscriptional regulation of MACC1 by miR-218 in this cell line. However, in dealing with MACC1 APA sites a broader screening is required between different cancer cell lines and entities for better understanding of this phenomenon.
A
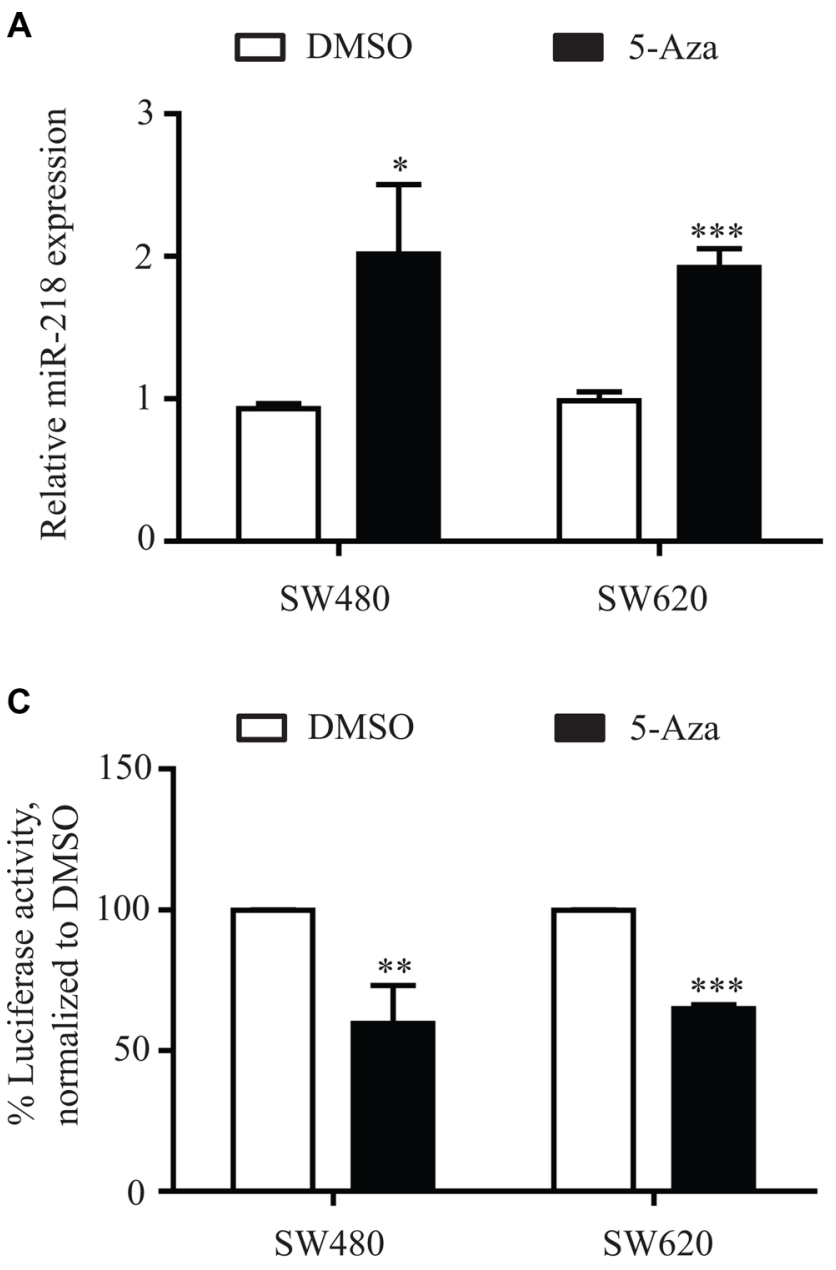

DV: Densitometry value
B

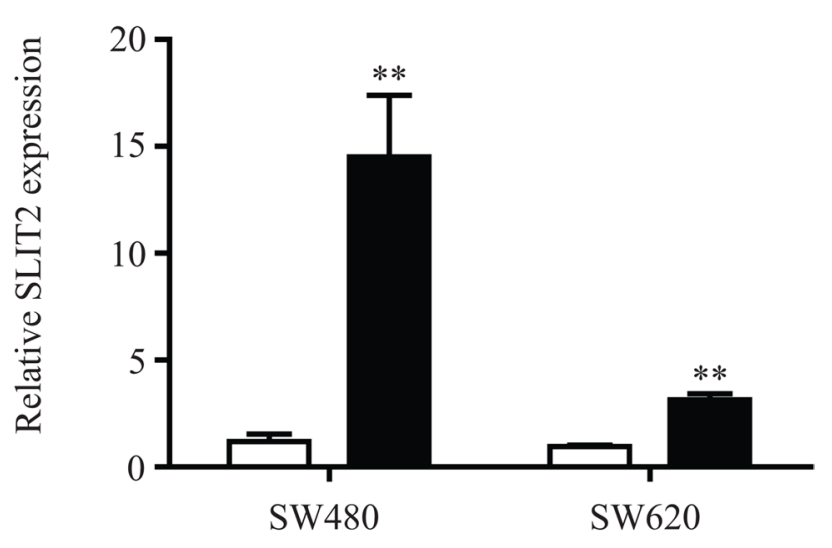

D

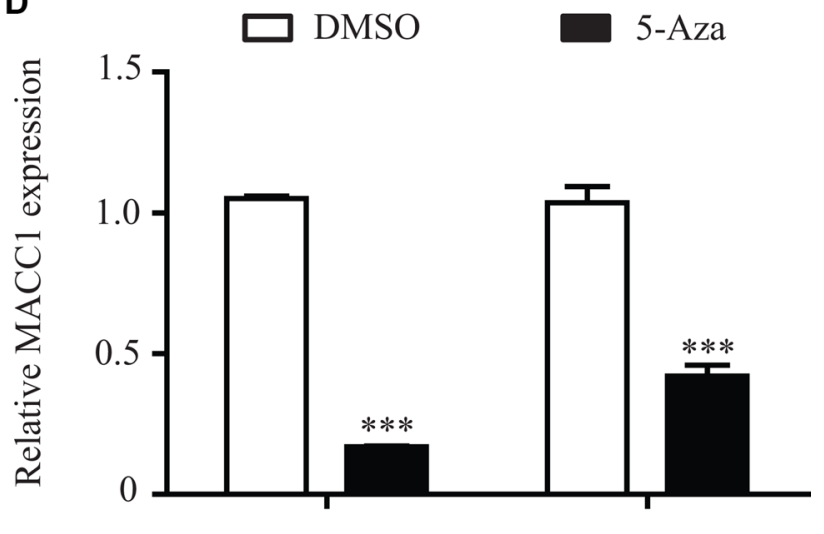

SW480

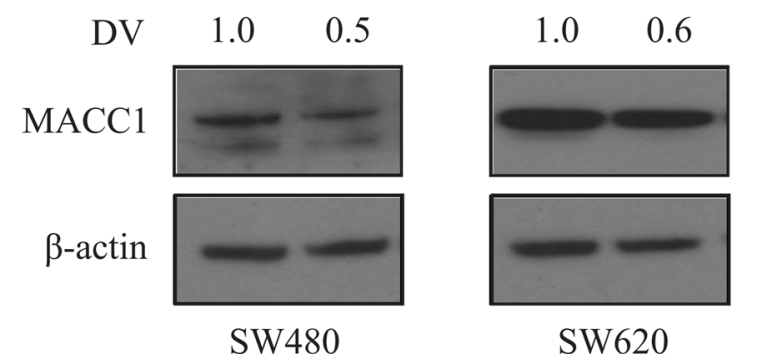

Figure 7: 5-Aza treatment induced miR-218 expression and downregulated MACC1 gene expression. SW480 and SW620 cells were treated with 5-Aza $(2 \mu \mathrm{M})$ for 3 days and total RNA and protein were isolated. (A, B) qRT-PCR revealed induction of miR-218 and its host gene SLIT2 expression. (C) Luciferase activity of MACC1-3'-UTR was significantly reduced after 5-Aza (2 $\mu$ M). (D) qRTPCR and Western blot analysis revealed inhibition of MACC1 expression in the 5-Aza treated samples compared to DMSO treated controls. RNUB6, RPII and $\beta$-actin served as internal controls. Densitometric analysis of MACC1 protein bands normalized to $\beta$-actin represented as a mean value of triplicates, in comparison to the respective control. 


\section{DISCUSSION}

In this study, we report that the tumor suppressor miR-218 post-transcriptionally downregulates MACC1. Expression of miR-218 is inversely correlated with the expression of MACC1 in a panel of CRC cell lines. miR-218 and MACC1 expression were significantly down- or upregulated respectively in a cohort of CRC tumor specimens. In vitro ectopic overexpression of miR-218 significantly inhibited the luciferase activity of MACC1-3'-UTR and MACC1 protein expression, as well as MACC1-induced migration, invasion and colony formation in CRC and gastric cancer cells. miR-218 and its host gene SLIT2 expression levels are positively correlated but there was no significant differences in miR-218 expression between metachronous metastasis positive and negative CRC tumor specimens. Secondly, miR-218 host genes SLIT2 and SLIT3 promoters are hypermethylated in the majority of CRC cell lines and tumor specimens. 5-Aza treatment significantly induced the expression of SLIT2 and miR-218 expression and inhibited the MACC1-3'-UTR luciferase activity and MACC1 expression. We also determined that MACC1 possesses alternative polyadenylation sites, which determines the availability of the 3 '-UTR for the posttranscriptional regulation by miRs.

miR-218 is an intronic miR of SLIT2 and SLIT3, which are epigenetically silenced in different cancer cells and tissues [30, 34, 39]. In parallel, a downregulation of miR-218 was also reported in various cancers entities like esophageal, hepatocellular, pancreatic, gallbladder, osteosarcoma, nasopharayngeal, colorectal, non-small cell lung cancer and breast cancer, which could be due to the epigenetic silencing of its host gene in the tumor cells $[28,29,31,34,40-45]$. Patients diagnosed with malignant glioma, gastric or colorectal cancer showing a low miR-218 expression had a shorter disease-free survival $[31,46,47]$. On the other hand, high MACC1 expression was shown to be prognostic for shorter survival in several entities $[8,11,48,49]$. In this present study, we also found miR-218 and MACC1 gene expression was significantly down- or upregulated, respectively, in CRC tumor specimens. In support of this inverse regulation of these two genes, luciferase reporter assay, qRT-PCR and Western blot analysis confirmed the post-transcriptional regulation of MACC1 by miR-218 in both CRC and gastric cancer cell lines.

miR-218 is a post-transcriptional regulator of the receptor Roundabout1 (Robo1) and acts via inhibiting the SLIT-Robo1-mediated tumor migration, invasion in different cancer entities [29, 47]. The epigenetic silencing of miR-218 leads to Robo1 overexpression and activation of the signaling axis after its interaction with SLIT2 $[29,50]$. Along with Robo1, other molecules like receptor protein tyrosine phosphatase alpha (RPTP $\alpha$ ), myocyte enhancer factor 2D (MEF2D), and runt-related transcription factor 2 (RUNX2) are post-transcriptional target molecules of miR-218, which are known to induce cancer metastasis like MACC1 [1, 50-52]. Rescue experiments with MACC1 overexpression or knock-down of MACC1 and miR-218 clearly revealed that MACC 1 as a novel target of miR-218 is at least in part responsible for the significant reduction of migration, invasion and colony formation by miR-218 in CRC and gastric cancer cell lines [1, 15, 17]. EMT plays a major role in solid cancer tumor progression, which is triggered due to transcriptional preprograming [53]. MACC1 is known to induce c-MET as receptor tyrosine kinase involved in EMT and key transcriptional regulators like TWST1/2 [1,54]. MACC 1 is also a posttranscriptional target of another miR, namely miR-338-3p, which targets the important EMT initiating transcription factor ZEB2 [26]. Like miR-338-3p, miR-218 is also a key EMT regulator, which targets for example ZEB2 and the mesenchymal marker N-cadherin [28]. In tumor tissues, downregulation of the MACC1 post-transcriptional regulators, miR-218 and miR-338-3p, could be reasons for the MACC1 overexpression and its mediated EMT, cancer metastasis formation and drug resistance $[28,54,55]$.

A

3’UTR of MACC1

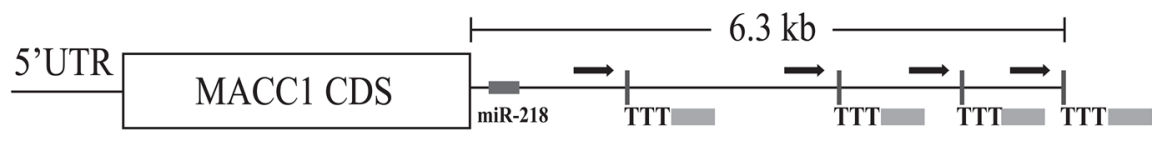

$$
\begin{aligned}
& \text { UTR: Untranslated region } \\
& \text { CDS: Coding sequence } \\
& \text { miR-218 seed sequence } \\
& \longrightarrow \text { Specific forward primer } \\
& \text { OTTigo dT primer with } \\
& \text { unique anchor sequence } \\
& \text { APA: Alternative polyadenylation }
\end{aligned}
$$



MACC1 3'UTR: $\quad \sim 2.3 \mathrm{~kb} \quad \sim 4.9 \mathrm{~kb} \quad \sim 5.7 \mathrm{~kb} \quad \sim 6.3 \mathrm{~kb}$

Figure 8: MACC1 possess alternative polyadenylation (APA) sites. (A) Schematic presentation of MACC1-3'-UTR with miR-218 seed sequence and the different preferential APA sites. (B) Gel electrophoresis of PCR products obtained from 3'-RACE PCR. 
5-Aza is used for treatment of different types of leukemia and leads to global demethylation and activation of previously silenced gene promoters. Here, treatment of the CRC cell lines with 5-Aza showed an induction of miR-218 and SLIT2 expression. The luciferase activity of MACC1-3'-UTR, MACC1 mRNA and protein expression were reduced in 5-Aza treated samples compared to DMSO controls. These results suggest that an epigenetic inhibition of miR-218 by hypermethylation of the SLIT2 and SLIT3 promoter could be one of the reasons for MACC1 upregulation and its mediated poor survival of CRC patients and other cancer entities. Further, we haven't observed any significant difference in miR-218 expression between metachronous metastasis positive and negative specimens. This suggests that downregulation of miR-218 and MACC1 upregulation are early events during cancer development even before metastasis. In previous studies, the MACC1 expression was not tumorstage dependent which supports our findings $[1,2,56]$. In general, our findings strongly support the existing literature that miR-218 is a tumor suppressor gene and MACC1 is an oncogene [1, 57-62].

The 3 '-end of eukaryotic mRNAs possess a long stretch of untemplated adenosines termed as poly(A) tail, which plays a major role in processing of 3 '-ends and stability of mRNAs [63, 64]. Recent advances in RNA sequence and transcriptome sequencing methods revealed that most of the human genes contain more than one $\operatorname{poly}(\mathrm{A})$ site [38]. The preferential poly(A) sites determines the stability, cellular localization and translational efficiency of genes, since the 3'-UTR serves as a docking site for regulatory miRNAs and RNA binding proteins $[65,66]$. Lin et al. recently reported that a large fraction of mRNAs (around 30\%) possess APA sites in $3^{\prime}$-UTRs based on the cell type [36]. Secondly, a comparison of APA sites between the cultured mammary epithelial cell line MCF10A and the breast cancer cell lines MCF7 and MDA-MB-231 revealed that cancer cells showed in general shorter 3 '-UTRs [35]. This could mean that these cells harbor less miRNA binding sites, which could alter the post-transcriptional regulation of cancer-relevant genes. Similarly, MACC1 showed four APA sites in SW620 cells and among them the $5.7 \mathrm{~kb}$ $3^{\prime}$-UTR is the most prominent one. Since, it is known that MACC1 is upregulated in different cancer entities. One could speculate that in general this APA mechanism might also add regulatory complexity of this gene in tumors.

In conclusion, all these findings highlight the pivotal role of miR-218 in various aspects of MACC1 expression regulation and $\mathrm{MACC} 1-$ mediated $\mathrm{CRC}$ progression. Translated into clinical practice, the determination of miR218 and MACC1 expression in tumors could be used for better therapeutic designs. Induced MACC1 expression positively and miR-218 expression negatively mitigate the cancer stem cell functions, which are responsible for the tumor formation, growth and metastasis and resistance to chemotherapy $[1,3,67]$. Including our previous studies on MACC1 and other MACC1 and miR-218 published studies demonstrated that high MACC1 and low miR218 expressing cancer cells are resistant to chemotherapy [20, 55, 68, 69]. These accumulated evidences strongly suggest for a miR-218 replacement therapeutic approach for MACC1 high expressing CRC patients, which might resensitize patients for chemotherapy and increases the patient survival.

\section{MATERIALS AND METHODS}

\section{Cell lines, cultures and drugs}

Human CRC cell lines (RKO, HCT15, Colo320DM, HCT116, SW480, SW620, HT-29, Caco-2, WiDr and DLD-1) were purchased from American Type Culture Collection (ATCC; Manassas, VA) and Colo206f from German Collection of Microorganisms and Cell culture (DSMZ Leibniz Institute; Braunschweig, Germany). The gastric cancer cell line MKN-45 was kindly provided by the Experimental Pharmacology \& Oncology Berlin-Buch $\mathrm{GmbH}$ (EPO; Berlin, Germany). Cells were grown at $37^{\circ} \mathrm{C}$ with RPMI (Colo320DM, Colo206f, WiDr, SW480, HCT15) and DMEM (rest of the cells used for this study) media supplemented with 10\% fetal calf serum (FCS). Original stock solutions of 5-aza-2'-deoxycytidine (5-azadC (\#A2385), Sigma Chemical Co., St. Louis, MD) was stored at a concentration of $10 \mathrm{mM}$ at $-20^{\circ} \mathrm{C}$ and freshly dissolved in culture medium before use.

\section{miR, anti-miR and si-MACC1}

mirVana $^{\circledR}$ miRNA mimic miR-218-5p (ID: MC10328), mirVana ${ }^{\circledR}$ miRNA inhibitor anti-miR-218-5p (ID: MH10328), mirVana $^{\mathrm{TM}}$ Negative Control (\#4464058), Predesigned Silencer ${ }^{\circledR}$ Select si MACC1 (ID:s51181) and Silencer ${ }^{\circledR}$ Select siRNA negative control (\#4390843) were purchased from Ambion, USA.

\section{Patients and samples}

Fresh snap-frozen surgical specimens of tumor tissues and representative corresponding normal specimens from 59 CRC patients were collected with informed written consent (approved by Charité Ethics Committee, Charité-Universitätsmedizin, Berlin), preserved and processed as explained in our previous publications $[1,25]$. The main patients' characteristics are reported in Supplementary Table S1. None of the patients received pre-operatory chemo/radiation therapy and none of the researchers conducting gene expression and statistical analyses had access to disclosed clinical-pathological data. 


\section{Construction of $3^{\prime}$-UTR-luciferase plasmids and reporter assays}

The 6016 bp length 3'-UTR of MACC1 was amplified using cDNA from SW480 cells and cloned into the SacI and XhoI sites of the pmirGLO dual luciferase miRNA target expression vector (\#E1330, Promega, USA). With specific MACC1-3'-UTR sequencing primers, we checked for the orientation and accuracy of the $3^{\prime}$-UTR sequence. Specific miR-218 seed sequence were mutated using site directed mutagenesis kit (\#210518, QuickChange lightning site directed mutagenesis kit, Agilent technologies, USA). Primers used for cloning, mutation and sequencing of the 3'-UTR are presented in Supplementary Tables S2, S3 and S4, respectively. For reporter assays, cells were cotransfected using Lipofectamine 2000 (Invitrogen) with $0.5 \mu \mathrm{g}$ of dual luciferase construct along with $50 \mathrm{nM}$ of control-miR or miRs/anti-miRs. Reporter assays were performed as described in the company protocol of Dualluciferase assay-system (Promega). Briefly, after $48 \mathrm{~h}$ of transfection, cells were lysed using passive lysis buffer and readings were taken for luciferase and then renilla for normalization. Percentage of luciferase activity was calculated as explained before [70].

\section{DNA/RNA/Protein isolation and cDNA synthesis from cells and fresh snap-frozen CRC specimens}

For isolation of DNA and RNA from frozen tissues, cryosections were performed and every fifth section was stained with hematoxylin. Tumor cell areas were evaluated and marked by a pathologist. Tumor cells were removed from the unstained slides and DNA was extracted by using ChargeSwitch ${ }^{\circledR}$ gDNA Micro Tissue Kit (\#CS11203, Thermo Fisher), according to the manufacturer's instructions. Similarly, RNA was extracted from tissues and cancer cells by using TRIzol reagent (Invitrogen). From the cancer cells, DNA was isolated using QIAamp DNA Mini Kit (\#51304, Qiagen), according to the manufacturer's instructions. DNA and RNA quality and concentration were measured using the Nano drop (Thermo Scientific). $1 \mu \mathrm{g}$ of total RNA was used to synthesize cDNA using miScript II RT Kit (Qiagen). Expression of mature miR218 (MS00006769, Qiagen) and U6-snRNA (RNUB6) (MS00033740, Qiagen) were determined by the miScript SYBR Green PCR Kit (Qiagen), and normalized using the $2^{-\Delta \Delta \mathrm{Ct}}$ method relative to RNU6B. SLIT2 (QT00007784, Qiagen), MACC1 and RPII expression were measured as described above. SLIT2 and MACC1 expression were normalized to RPII expression. Primers are provided in Supplementary Table S5.

For protein extraction, cells were washed with PBS and lysed with RIPA buffer (50 mM TrisHCl [pH 7.5], $150 \mathrm{mM} \mathrm{NaCl}, 1 \%$ Nonidet P-40, supplemented with complete protease inhibitor tablets; Roche Diagnostics) for $30 \mathrm{~min}$ on ice. Protein estimation and Western blot analysis were performed as described by Juneja et al. using specific antibodies for MACC1 (\#Sigma-HPA020103) or $\beta$-actin (\#SIGMA-A1978) [25].

\section{Cell viability, migration, invasion and colony formation assay}

Cells were seeded in 6-well plates and transfected with $50 \mathrm{nM}$ control, miR-218 or anti-218 (Thermo Fisher Scientific) using Lipofectamine ${ }^{\circledR}$ RNAiMAX Reagent (Thermo Fisher Scientific) according to the manufacturer's instructions. Cells were seeded for cell viability, migration, invasion and colony formation assay $48 \mathrm{~h}$ after transfection.

For cell viability assay, $3.5 \times 10^{3}$ cells were seeded into 96-well plates. Quantification of cell viability was achieved using MTT (final concentration $0.5 \mathrm{mg} / \mathrm{ml}$, Sigma) colorimetric assay. The absorption values at 560 $\mathrm{nm}$ measured with the Infinite M200 Pro Reader (Tecan) were normalized to day 0 values and represented as foldchanges of the corresponding control. The assay was repeated at least two independent times each in triplicates.

Migration assay was performed using transwells (Costar) with $8 \mu \mathrm{m}$ pores. $3 \times 10^{5}$ cells were seeded per well and quantified $16 \mathrm{~h}$ after seeding using CellTiter-Glo ${ }^{\circledR}$ Luminescent Cell Viability Assay (Promega) according to the manufacturer's instructions. For invasion assay transwells were coated with Matrigel (final concentration $10 \mu \mathrm{g} / 100 \mu \mathrm{l}$, Corning) overnight at RT and performed the same way as described for migration assay. These assays were performed three independent times, each in triplicates.

Soft agar colony formation assay was used to analyze the effects of the miRNA on anchorageindependent cell proliferation. The bottom layer contained $0.4 \% \mathrm{w} / \mathrm{v}$ agarose in DMEM or RPMI 1640 medium including $10 \%$ FCS and was added into $6 \mathrm{~cm}$ cell culture dish with grids $\left(2 \mu \mathrm{m}^{2}, \mathrm{VWR}\right)$. The top layer contained $8 \times 10^{3}$ cells, $0.2 \% \mathrm{w} / \mathrm{v}$ agarose in DMEM or RPMI 1640 medium including $10 \%$ FCS and was added onto the solidified bottom layer. Cells were seeded as single cells into the soft agar and incubated in a humidified incubator at $37^{\circ} \mathrm{C}$ and $5 \% \mathrm{CO}_{2}$ for 14 days. Colonies were visualized by $10 \times$ magnification in the Zeiss AXIO microscope (Zeiss). Colonies of more than 4 cells were counted and represented as normalized to the control group. The assay was repeated three independent times.

\section{5-Aza-2'-Deoxycytidine (5-aza-dC) treatment of cells, bisulfite conversion of DNA and methylation analysis}

5'-aza-dC (5-Aza) treatment, bisulfite conversion and methylation analyses (PCR was performed using HotStarTaq Plus DNA Polymerase (\#203605, Qiagen), were performed as described previously [70, 71]. 
MACC1, SLIT2 and miR-218 expression was quantified in comparison to DMSO-treated samples. CpG islands upstream of the TSS (Transcription start site) or pri-miR start site were determined with the $\mathrm{CpG}$ island searcher (http://www.uscnorris.com/cpgislands2/cpg.aspx), and PCR primers were designed using the Methprimer software (http://www.urogene.org/methprimer) approximately $1000 \mathrm{bp}$ upstream to the SLIT2, SLIT3 and miR-218 TSS. Primer sequences are provided in Supplementary Table S6.

\section{3'-Race experiment}

Total RNA was isolated using the Universal RNA Purification Kit (Roboklon) according to the manufacturer's instructions including the DNase I digest step. $1 \mu \mathrm{g}$ of RNA isolated from SW620 cells was mixed with $5 \mu \mathrm{M}$ oligo-dT primer and $500 \mu \mathrm{M}$ dNTPs and incubated at $65^{\circ} \mathrm{C}$ for $5 \mathrm{~min}$. After cooling down on ice for $1 \mathrm{~min}$ a reaction mix for reverse transcription was prepared using $1 \times$ RT buffer, $5 \mu \mathrm{M}$ DTT, 40 U RiboBlock, $200 \mathrm{U}$ SuperScriptIII (Thermo Scientific) and incubated at $50^{\circ} \mathrm{C}$ for $60 \mathrm{~min}$ and afterwards at $70^{\circ} \mathrm{C}$ for $15 \mathrm{~min}$. Ampli Taq Gold (Thermo Scientific) was used for cDNA amplification according to the manufacturer's instructions. The PCR product was run on an agarose gel to visualize the different polyadenylated versions of the MACC1-3'-UTR. Primer sequences are provided in Supplementary Table S7.

\section{Statistical analysis}

All statistical analyses were performed with IBM ${ }^{\circledR}$ SPSS $^{\circledR}$ Statistics 21 or GraphPad Prism version 5 (La Jolla). The comparison of two different groups was done by Student's $t$-test. Comparison of three or more different treated groups was performed by one-way analysis of variance (ANOVA) and Bonferroni post hoc multiple comparison test. The non-parametric Spearmen correlation test was used for correlation analysis of MACC1 mRNA and miR-218 expression in CRC cell lines. Linear regression model was used to analyse the correlation between miR-218 and its host gene expression, SLIT2. MACC1 mRNA and miR-218 expression levels in tumor and normal specimen were examined using box and Whisker plots. Significant differences between two different groups were determined by Mann-Whitney $U$-test. All significance tests were two sided, and $P$-values less than 0.05 were defined as statistically significant.

\section{ACKNOWLEDGMENTS AND FUNDING}

This work was supported by the German Cancer Consortium (DKTK) to GM and US.

\section{CONFLICTS OF INTEREST}

There are no conflicts to disclose.

\section{REFERENCES}

1. Stein U, Walther W, Arlt F, Schwabe H, Smith J, Fichtner I, Birchmeier W, Schlag PM. MACC1, a newly identified key regulator of HGF-MET signaling, predicts colon cancer metastasis. Nat Med. 2009; 15:59-67.

2. Ren B, Zakharov V, Yang Q, McMahon L, Yu J, Cao W. $\mathrm{MACC} 1$ is related to colorectal cancer initiation and earlystage invasive growth. Am J Clin Pathol. 2013; 140:701-707.

3. Lemos C, Hardt MS, Juneja M, Voss C, Förster S, Jerchow B, Haider W, Bläker H, Stein U. MACC1 Induces Tumor Progression in Transgenic Mice and Colorectal Cancer Patients via Increased Pluripotency Markers Nanog and Oct4. Clin Cancer Res. 2016; 22:2812-24. doi: 10.1158/1078-0432.CCR-15-1425.

4. Arlt F, Stein U. Colon cancer metastasis: MACC1 and Met as metastatic pacemakers. International Journal of Biochemistry and Cell Biology. 2009; 41:2356-2359.

5. Yamamoto H, Miyoshi N, Mimori K, Hitora T, Tokuoka M, Fujino S, Ellis H, Ishii H, Noura S, Ohue M, Yano M, Doki Y, Mori M. MACC1 expression levels as a novel prognostic marker for colorectal cancer. Oncol Lett. 2014; 8:2305-2309.

6. Galimi F, Torti D, Sassi F, Isella C, Corà D, Gastaldi S, Ribero D, Muratore A, Massucco P, Siatis D, Paraluppi G, Gonella F, Maione F, et al. Genetic and expression analysis of MET, MACC1, and HGF in metastatic colorectal cancer: Response to Met inhibition in patient xenografts and pathologic correlations. Clin Cancer Res. 2011; 17:3146-3156.

7. Koelzer VH, Herrmann P, Zlobec I, Karamitopoulou E, Lugli A, Stein U. Heterogeneity analysis of Metastasis Associated in Colon Cancer 1 (MACC1) for survival prognosis of colorectal cancer patients: a retrospective cohort study. BMC Cancer. 2015; 15:1-11.

8. Ilm K, Kemmner W, Osterland M, Burock S, Koch G, Herrmann P, Schlag PM, Stein U. High MACC1 expression in combination with mutated KRAS G13 indicates poor survival of colorectal cancer patients. Mol Cancer. 2015; 14:1-7.

9. Wang G, Fu Z, Li D. MACC1 overexpression and survival in solid tumors: a meta-analysis. Tumor Biol. 2014; 36:1055-1065.

10. Wu Z, Zhou R, Su Y, Sun L, Liao Y, Liao W. Prognostic Value of MACC1 in Digestive System Neoplasms: A Systematic Review and Meta-Analysis. Biomed Res Int. 2015; 2015:252043.

11. Stein U. MACC1 - a novel target for solid cancers. Expert Opin Ther Targets. 2013; 17:1039-1052.

12. Sun D-W, Zhang Y-Y, Qi Y, Liu G-Q, Chen Y-G, Ma J, Lv G-Y. Prognostic and clinicopathological significance of MACC1 expression in hepatocellular carcinoma patients: a meta-analysis. Int J Clin Exp Med. 2015; 8:4769-4777.

13. Pichorner A, Sack U, Kobelt D, Kelch I, Arlt F, Smith J, Walther W, Schlag PM, Stein U. In vivo imaging of 
colorectal cancer growth and metastasis by targeting MACC1 with shRNA in xenografted mice. Clin Exp Metastasis. 2012; 29:573-583.

14. Zheng Z, Gao S, Yang Z, Xie H, Zhang C, Lin B, Wu L, Zheng S, Zhou L. Single nucleotide polymorphisms in the metastasisassociated in colon cancer-1 gene predict the recurrence of hepatocellular carcinoma after transplantation. Int J Med Sci. 2014; 11:142-150.

15. Sun L, Duan J, Jiang Y, Wang L, Huang N, Lin L, Liao Y, Liao W, Li Sun, Jiangman Duan, Yaqi Jiang, Lin Wang, $\mathrm{Na}$ Huang, et al. Metastasis-associated in colon cancer-1 upregulates vascular endothelial growth factor-C/D to promote lymphangiogenesis in human gastric cancer. Cancer Lett. Cancer Lett. 2015; 357:242-253.

16. Yao Y, Dou C, Lu Z, Zheng X, Liu Q. MACC1 Suppresses Cell Apoptosis in Hepatocellular Carcinoma by Targeting the HGF/c-MET/AKT Pathway. Cell Physiol Biochem. 2015; 35:983-996.

17. Zhen T, Dai S, Li H, Yang Y, Kang L, Shi H, Zhang F, Yang D, Cai S, He Y, Liang Y, Han A. MACC1 promotes carcinogenesis of colorectal cancer via $\beta$-catenin signaling pathway. Oncotarget. 2014; 5:3756-3769. doi: 10.18632/ oncotarget.1993.

18. Meng F, Li H, Shi H, Yang Q, Zhang F, Yang Y, Kang L, Zhen T, Dai S, Dong Y, Han A. MACC1 DownRegulation Inhibits Proliferation and Tumourigenicity of Nasopharyngeal Carcinoma Cells through Akt/ $\beta$-Catenin Signaling Pathway. PLoS One. 2013; 8: e60821

19. Wang L, Wu Y, Lin L, Liu P, Huang H, Liao W, Zheng D, Zuo Q, Sun L, Huang N, Shi M, Liao Y, Liao W. Metastasisassociated in colon cancer- 1 upregulation predicts a poor prognosis of gastric cancer, and promotes tumor cell proliferation and invasion. Int J Cancer. 2013; 133:1419-1430.

20. Wang G, Kang MX, Lu WJ, Chen Y, Zhang B, Wu YL. MACC1: A potential molecule associated with pancreatic cancer metastasis and chemoresistance. Oncol Lett. 2012; 4:783-791.

21. Lin L, Huang H, Liao W, Ma H, Liu J, Wang L, Huang N, Liao Y, Liao W. MACC1 supports human gastric cancer growth under metabolic stress by enhancing the Warburg effect. Oncogene. 2015; 34:2700-2710.

22. Abba M, Mudduluru G, Allgayer H. MicroRNAs in cancer: small molecules, big chances. Anticancer Agents Med Chem. 2012; 12:733-743.

23. Valeri N, Vannini I, Fanini F, Calore F, Adair B, Fabbri M. Epigenetics, miRNAs, and human cancer: A new chapter in human gene regulation. Mammalian Genome. 2009; 20: 573-580.

24. Mudduluru G, George-William JN, Muppala S, Asangani IA, Kumarswamy R, Nelson LD, Allgayer H. Curcumin regulates miR-21 expression and inhibits invasion and metastasis in colorectal cancer. Biosci Rep. 2011; 31:185-197.

25. Juneja M, Ilm K, Schlag PM, Stein U. Promoter identification and transcriptional regulation of the metastasis gene MACC1 in colorectal cancer. Mol Oncol. 2013; 7:929-943.

26. Huang $\mathrm{N}, \mathrm{Wu} \mathrm{Z}$, Lin L, Zhou M, Wang L, Ma H, Bin J, Liao Y, Liao W. MiR-338-3p inhibits epithelialmesenchymal transition in gastric cancer cells by targeting ZEB2 and MACC1 / Met / Akt signaling. Oncotarget. 2015; 6:15222-15234. doi: 10.18632/oncotarget.3835.

27. Migliore C, Martin V, Leoni VP, Restivo A, Atzori L, Petrelli A, Isella C, Zorcolo L, Sarotto I, Casula G, Comoglio PM, Columbano A, Giordano S. MiR-1 downregulation cooperates with MACC1 in promoting MET overexpression in human colon cancer. Clin Cancer Res. 2012; 18:737-747.

28. Mudduluru G, Abba M, Batliner J, Patil N, Scharp M, Lunavat TR, Leupold JH, Oleksiuk O, Juraeva D, Thiele W, Rothley M, Benner A, Ben-Neriah Y, et al. A systematic approach to defining the microRNA landscape in metastasis. Cancer Res. 2015; 75:3010-3019

29. Alajez NM, Lenarduzzi M, Ito E, Hui ABY, Shi W, Bruce J, Yue S, Huang SH, Xu W, Waldron J, O’Sullivan B, Liu FF. miR-218 suppresses nasopharyngeal cancer progression through downregulation of survivin and the SLIT2-ROBO1 pathway. Cancer Res. 2011; 71:2381-2391.

30. Narayan G, Goparaju C, Arias-Pulido H, Kaufmann AM, Schneider A, Dürst M, Mansukhani M, Pothuri B, Murty VV. Promoter hypermethylation-mediated inactivation of multiple Slit-Robo pathway genes in cervical cancer progression. Mol Cancer. 2006; 5:16.

31. Yu H, Gao G, Jiang L, Guo L, Lin M, Jiao X, Jia W, Huang J. Decreased expression of miR-218 is associated with poor prognosis in patients with colorectal cancer. Int $\mathrm{J}$ Clin Exp Pathol. 2013; 6:2904-2911.

32. Song L, Huang Q, Chen K, Liu L, Lin C, Dai T, Yu C, Wu Z, Li J. MiR-218 inhibits the invasive ability of glioma cells by direct downregulation of IKK- $\beta$. Biochem Biophys Res Commun. 2010; 402:135-140.

33. Zhu K, Ding H, Wang W, Liao Z, Fu Z, Hong Y, Zhou Y, Zhang C-Y, Chen X. Tumor-suppressive miR-218-5p inhibits cancer cell proliferation and migration via EGFR in non-small cell lung cancer. Oncotarget. 2016; 7:28075-85. doi: 10.18632/oncotarget.8576.

34. Yang M, Liu R, Li X, Liao J, Pu Y, Pan E, Wang Y, Yin L. Epigenetic repression of miR-218 promotes esophageal carcinogenesis by targeting ROBO1. Int J Mol Sci. 2015; 16:27781-27795.

35. Fu Y, Sun Y, Li Y, Li J, Rao X, Chen C, Xu A. Differential genome-wide profiling of tandem 3' UTRs among human breast cancer and normal cells by high-throughput sequencing. Genome Res. 2011; 21:741-747.

36. Lin Y, Li Z, Ozsolak F, Kim SW, Arango-Argoty G, Liu TT, Tenenbaum SA, Bailey T, Monaghan AP, Milos PM, John B. An in-depth map of polyadenylation sites in cancer. Nucleic Acids Res. 2012; 40:8460-8471.

37. Morris AR, Bos A, Diosdado B, Rooijers K, Elkon R, Bolijn AS, Carvalho B, Meijer GA, Agami R. Alternative 
cleavage and polyadenylation during colorectal cancer development. Clin Cancer Res. 2012; 18:5256-5266.

38. Wang ET, Sandberg R, Luo S, Khrebtukova I, Zhang L, Mayr C, Kingsmore SF, Schroth GP, Burge CB. Alternative isoform regulation in human tissue transcriptomes. Nature. 2008; 456:470-476.

39. Guan H, Wei G, Wu J, Fang D, Liao Z, Xiao H, Li M, Li Y. Down-regulation of miR-218-2 and its host gene SLIT3 cooperate to promote invasion and progression of thyroid cancer. J Clin Endocrinol Metab. 2013; 98:E1334-1344.

40. Zhang C, Ge S, Hu C, Yang N, Zhang J. MiRNA-218, a new regulator of HMGB1, suppresses cell migration and invasion in non-small cell lung cancer. Acta Biochim Biophys Sin. 2013; 45:1055-1061.

41. Lowery AJ, Miller N, Devaney A, McNeill RE, Davoren PA, Lemetre C, Benes V, Schmidt S, Blake J, Ball G, Kerin MJ. MicroRNA signatures predict oestrogen receptor, progesterone receptor and HER2/neu receptor status in breast cancer. Breast Cancer Res. 2009; 11:R27.

42. Yang L, Xu Q, Xie H, Gu G, Jiang J. Expression of serum miR-218 in hepatocellular carcinoma and its prognostic significance. Clin Transl Oncol. 2015.

43. Li B-S, Liu H, Yang W-L. Reduced miRNA-218 expression in pancreatic cancer patients as a predictor of poor prognosis. Genet Mol Res. 2015; 14:16372-16378.

44. Chandra V. MicroRNA aberrations: An emerging field for gallbladder cancer management. World J Gastroenterol. 2016; 22:1787-1799.

45. Taheriazam A, Talaei AJ, Jamshidi M, Shakeri M, Khoshbakht S, Yahaghi E, Shokrani M. Up-regulation of miR-130b expression level and down-regulation of miR218 serve as potential biomarker in the early detection of human osteosarcoma. Diagn Pathol. 2015; 10:184.

46. Cheng MW, Wang LL, Hu GY. Expression of microRNA-218 and its clinicopathological and prognostic significance in human glioma cases. Asian Pacific J Cancer Prev. 2015; 16:1839-1843.

47. Tie J, Pan Y, Zhao L, Wu K, Liu J, Sun S, Guo X, Wang B, Gang Y, Zhang Y, Li Q, Qiao T, Zhao Q, et al. MiR-218 inhibits invasion and metastasis of gastric cancer by targeting the robo1 receptor. PLoS Genet. 2010; 6:e1000879.

48. Ge Y, Meng X, Zhou Y, Zhang J, Ding Y. Positive MACC1 expression correlates with invasive behaviors and postoperative liver metastasis in colon cancer. Int J Clin Exp Med. 2015; 8:1094-1100.

49. Zhang K, Zhang Y, Zhu H, Xue N, Liu J, Shan C, Zhu Q. High expression of MACC1 predicts poor prognosis in patients with osteosarcoma. Tumor Biol. 2013; 35:1343-1350.

50. Lai X, Chen Q, Zhu C, Deng R, Zhao X, Chen C, Wang Y, Yu J, Huang J. Regulation of RPTPalpha-c-Src signalling pathway by miR-218. FEBS J. 2015; 282:2722-2734.

51. Song L, Li D, Zhao Y, Gu Y, Zhao D, Li X, Bai X, Sun Y, Zhang X, Sun H, Wang Y, Peng L. miR-218 suppressed the growth of lung carcinoma by reducing MEF2D expression. Tumour Biol. 2016; 37:2891-900.

52. Xie J, Yu F, Li D, Zhu X, Zhang X, Lv Z. MicroRNA-218 regulates cisplatin (DPP) chemosensitivity in non-small cell lung cancer by targeting RUNX2. Tumour Biol. 2016; 37:1197-1204.

53. Kalluri R. EMT: When epithelial cells decide to become mesenchymal-like cells. J Clin Invest. 2009; 119:1417-1419.

54. Wang L, Lin L, Chen X, Sun L, Liao Y, Huang N, Liao W. Metastasis-associated in colon cancer-1 promotes vasculogenic mimicry in gastric cancer by upregulating TWIST1/2. Oncotarget. 2015; 6:11492-11506. doi: 10.18632/oncotarget.3416.

55. Duan J, Sun L, Zhao L, Liao WW, Liao Y, Duan Jiangman, Sun Li, Zhao Liang, Liao Wenjun, Liu Jing, Liao Yulin LW. Participation of metastasis-associated in colon cancer-1 gene on lipogenesis and chemoresistance of gastric cancer. J Clin Oncol. 2014; 32:e15026.

56. Xie C, Wu J, Yun J, Lai J, Yuan Y, Gao Z, Li M, Li J, Song L. MACC1 as a prognostic biomarker for early-stage and AFP-normal hepatocellular carcinoma. PLoS One. 2013; 8:e64235.

57. Tu Y, Gao X, Li G, Fu H, Cui D, Liu H, Jin W, Zhang Y. MicroRNA-218 inhibits glioma invasion, migration, proliferation, and cancer stem-like cell self-renewal by targeting the polycomb group gene Bmi1. Cancer Res. 2013; 73:6046-6055.

58. Lu Y, Zhang L, Waye MMY, Fu W, Zhang J. MiR-218 mediates tumorigenesis and metastasis: Perspectives and implications. Exp Cell Res. 2015; 334:173-182.

59. Jin J, Cai L, Liu Z-M, Zhou X-S. miRNA-218 inhibits osteosarcoma cell migration and invasion by downregulating of TIAM1, MMP2 and MMP9. Asian Pac J Cancer Prev. 2013; 14:3681-3684.

60. Sheng XJ, Li Z, Sun M, Wang ZH, Zhou DM, Li JQ, Zhao Q, Sun XF, Liu QC. MACC1 induces metastasis in ovarian carcinoma by upregulating hepatocyte growth factor receptor c-MET. Oncol Lett. 2014; 8:891-897.

61. Li H-F, Liu Y-Q, Shen Z-J, Gan X-F, Han J-J, Liu Y-Y, Li H-G, Huang Z-Q. Downregulation of MACC1 inhibits invasion, migration and proliferation, attenuates cisplatin resistance and induces apoptosis in tongue squamous cell carcinoma. Oncol Rep. 2015; 33:651-660.

62. Schmid F, Wang Q, Huska MR, Andrade-Navarro MA, Lemm M, Fichtner I, Dahlmann M, Kobelt D, Walther W, Smith J, Schlag PM, Stein U. SPON2, a newly identified target gene of MACC1, drives colorectal cancer metastasis in mice and is prognostic for colorectal cancer patient survival. Oncogene. 2015.

63. Edmonds M, Abrams R. Polynucleotide biosynthesis: formation of a sequence of adenylate units from adenosine triphosphate by an enzyme from thymus nuclei. J Biol Chem. 1960; 235:1142-1149.

64. Proudfoot NJ. Ending the message: Poly(A) signals then and now. Genes Dev. 2011; 25:1770-1782. 
65. Fabian MR, Sonenberg N, Filipowicz W. Regulation of mRNA translation and stability by microRNAs. Annu Rev Biochem. 2010; 79:351-379.

66. Andreassi C, Riccio A. To localize or not to localize: mRNA fate is in 3'UTR ends. Trends Cell Biol. 2009; 19:465-474

67. Wang B, Liu Y, Luo F, Xu Y, Qin Y, Lu X, Xu W, Shi L, Liu Q, Xiang Q. Epigenetic silencing of microRNA-218 via EZH2-mediated $\mathrm{H} 3 \mathrm{~K} 27$ trimethylation is involved in malignant transformation of HBE cells induced by cigarette smoke extract. Arch Toxicol. 2016; 90:449-461.

68. Li PL, Zhang X, Wang LL, Du LT, Yang YM, Li J, Wang CX. MicroRNA-218 is a prognostic indicator in colorectal cancer and enhances 5-fluorouracil-induced apoptosis by targeting BIRC5. Carcinogenesis. 2015; 36:1484-1493.
69. Shang C, Hong Y, Guo Y, Liu Y, Xue Y. Influence of the MACC1 gene on sensitivity to chemotherapy in human U251 glioblastoma cells. 2015; 16:195-199.

70. Mudduluru G, Allgayer $H$. The human receptor tyrosine kinase Axl gene- - promoter characterization and regulation of constitutive expression by $\mathrm{Sp} 1, \mathrm{Sp} 3$ and $\mathrm{CpG}$ methylation. Biosci Rep. 2008; 28:161-176.

71. Ceppi P, Mudduluru G, Kumarswamy R, Rapa I, Scagliotti GV, Papotti M, Allgayer H. Lossof miR200c expression induces an aggressive, invasive, and chemoresistant phenotype in non-small cell lung cancer. Mol Cancer Res. 2010; 8:1207-1216. 